\title{
CIÊNCIAPNATURA 35橤
}

\section{Fotografias hemisféricas em estudos microclimáticos: Referencial teórico-conceitual e aplicações}

\author{
Hemispherical photographs in microclimatic studies: \\ theoretical-conceptual and applications \\ Emerson Galvani ${ }^{* 1}$ e Nádia Gilma Beserra de Lima ${ }^{2}$ \\ ${ }^{1}$ Doutor, Departamento de Geografia, Universidade de São Paulo, São Paulo, Brasil \\ ${ }^{2}$ Doutoranda em Geografia Física, Universidade de São Paulo, São Paulo, Brasil
}

\begin{abstract}
Resumo
O objetivo deste artigo é apresentar uma releitura acerca das potencialidades e limitações do uso de fotografias hemisféricas em estudos microclimáticos. O uso dessa tecnologia ainda é incipiente nos estudos de Climatologia Geográfica. São discutidos as formas de obtenção das fotografias hemisféricas e o uso na estimativa do índice de área foliar e abertura do dossel da vegetação. Resultados para os manguezais do Litoral Sul do estado de São Paulo são representados e analisados. O uso de fotografias hemisféricas e a estimativa de parâmetros da cobertura vegetal, como índice de área foliar (IAF) e abertura do dossel, representam uma forma de avaliação das interações que ocorrem na interface superfície-dossel. As dificuldades e subjetividades não impedem o seu uso dentro dos estudos microclimáticos desde que considerados alguns aspectos das condições de controle: luminosidade, hora do dia, orientação e período do ano.
\end{abstract}

Palavras-chave: Manguezal, escala microclimática, índice de área foliar.

\begin{abstract}
The objective of this paper is to present a new reading about the potential and limitations of hemispherical photographs in microclimatic studies. The use of this technology is still in initial studies on Geography Climatology. Forms of production and the use of hemispherical photographs in estimating leaf area index and canopy openness of vegetation are discussed. The results for the mangroves of the South Coast of São Paulo are represented and analyzed in this article. The hemispherical photographs and parameter estimation of vegetation cover, such as leaf area index (LAI) and canopy openness, represent a form of assessment of the interactions that occur on the surfacecanopy interface. Subjectivities and difficulties do not prevent its use within the microclimate studies only if are considered some aspects of the conditions of control: brightness, time of day, orientation.
\end{abstract}

Keywords: Mangrove, microclimatic scale, leaf area index.

* egalvani@usp.br

Recebido: 19/03/2014 Aceito: 19/03/2014 


\section{Introdução}

\subsection{0 dossel da vegetação e suas interações}

$\mathrm{A}$ estrutura vertical de uma floresta, que depende da composição das espécies, das associações ecológicas e da idade da vegetação, determina seu microclima. A influência climática de uma floresta pode ser explicada em termos da geometria da floresta, incluindo características morfológicas, porte, cobertura, idade e estratificação. As características morfológicas incluem a quantidade de ramificações, a periodicidade do crescimento (perene, semi-decídua ou decídua), junto com o porte, a densidade, idade e a textura das folhas. A cobertura do dossel determina a obstrução física para às trocas de radiação e escoamento do ar (BARRY; CHORLEY, 2013). Para Barry e Chorley (2013), é adequado descrever os efeitos climáticos das áreas de florestas em termos da modificação que causam nas transferências de energia, no escoamento do ar, na umidade e na temperatura do ar.

A cobertura promovida pelo dossel controla a quantidade, qualidade e distribuição temporal e espacial da radiação solar incidente, refletindo posteriormente em níveis diferenciados de umidade, temperatura e condições de umidade do solo, além de promover a interceptação das chuvas, reduzindo o impacto direto sobre o solo, alterando, portanto, as condições microclimáticas do ambiente. A quantidade e a forma de orientação da vegetação em um determinado ambiente determinam a densidade de uma cobertura e constituem os fatores primários não só no regime de radiação como também nas trocas gasosas e energéticas entre o meio vegetal e a atmosfera (MARQUES FILHO, 1997). Dessa forma, a cobertura é um dos determinantes do "micro-habitat" de uma floresta, influenciando o crescimento e sobrevivência de plântulas, o processos de oxidação da matéria orgânica, a composição florística e controlando processos erosivos (MELO et al., 2007), portanto a cobertura vegetal atua diretamente nas condições microclimáticas do ambiente.

Assim, a caracterização da cobertura vegetal, em sua estrutura e distribuição espacial, representa o ponto inicial para estudos de fenômenos físicos e fisiológicos que ocorrem em seu interior.

Nos estudos microclimáticos, dentro Climatologia Geográfica, com ênfase em áreas florestadas, o estudo da cobertura vegetal com uso de fotografias hemisféricas ainda é incipiente. Estudo de Salvi-Sakamoto (2001) demonstrou o uso destes procedimentos em ambientes urbanos. Essa autora utilizou-se da fotografia hemisférica para obter a configuração do céu, que indica quanto do céu está obstruído por elementos do ambiente (edifícios e árvores, principalmente no caso de ambiente urbanos), acima de um ponto qualquer da superfície terrestre. $\mathrm{O}$ uso desta tecnologia é mais comum nas áreas de Ecologia, Biologia, Agronomia utilizada para obtenção do índice de área foliar e/ou estimativa da transmissão da radiação solar para dentro do ambiente.

O objetivo deste artigo é apresentar uma revisão bibliográfica acerca do uso de fotografias hemisféricas em estudos microclimáticos indicando as potencialidades e limitações do uso desta tecnologia. Apresenta ainda uma leitura acerca dos referencias teóricos e as técnicas de utilização destes procedimentos e alguns resultados preliminares referentes a dados obtidos em manguezais no Litoral Sul de São Paulo.

\section{Objeto de estudo: o índice de área foliar e a abertura do dossel}

O índice de área foliar (IAF) de uma cobertura vegetal definido por Watson (1974) como a área foliar integrada do dossel por unidade de superfície projetada no solo (m2/m2), é computado ao considerar a superfície de apenas uma das faces das folhas. Esse índice é resultante das respostas ecofisiológicas das plantas às condições químicas, físicas e biológicas do solo; às condições do microclima; as condições bióticas como herbivoria, competição e a interdependências desses fatores nos diferentes estágios sucessionais da vegetação (WANDELLI; MARQUES FILHO, 1999).

Existem duas categorias de métodos para estimar o IAF: métodos diretos e indiretos. Os métodos diretos, na maioria destrutivos e demorados, implicam na colheita das folhas ou de biomassa, de difícil obtenção e, por vezes, de impossível execução principalmente em comunidades arbóreas. Ou ainda, a avaliação quantitativa do regime de luz em ambiente de floresta por medição direta consume tempo e dinheiro, devido a considerável variação espacial e temporal desse fator ambiental (Jarčuška, 2008).

Por esta razão, foram desenvolvidos vários métodos indiretos que visam determinar a quantidade acessível de radiação solar, com base na avaliação da estrutura da copa. Um deles é o método de fornecimento com a avaliação de fotografias realizadas a $180^{\circ}$ " olho de peixe " lentes (JENNINGS et al ., 1999). Uma fotografia hemisférica (Fig. 1) mapeia o tamanho, a magnitude e distribuição das aberturas da copa em relação ao local em que a fotografia foi obtida (JELASKA et al. , 2006). O resultado é que, além da avaliação indireta da luz do sub-dossel, o método também pode ser utilizado para avaliar as características da estrutura da copa (abertura do dossel e índice de área foliar efetiva). Desta forma, a fotografia hemisférica é utilizada para determinar a geometria e a posição da abertura de dossel, a passagem da radiação solar em períodos sazonais, e subsequentemente, calcular indiretamente vários parâmetros de luminosidade abaixo do dossel, permitindo inferir sobre as propriedades do dossel (ROXBURGH; KELLY, 1995). Assim, a fotografia hemisférica é uma das técnicas que pode ser utilizada para medição da interceptação da radiação solar incidente sob o dossel. 
A primeira objetiva hemisférica foi fabricado por HILL, em 1924, com o objetivo de estudar a nebulosidade. Ecologistas florestais começaram a usar os métodos cerca de 35 anos mais tarde (EVANS E COOMBE, 1959 apud JELASKA et al., 2006). Muito da fundamentação teórica da fotografia hemisférica foi desenvolvido por Anderson et al., (1964, 1974), em grande parte utilizando análise manual de fotografia. Desde então, tem se analisado o uso computacional para as fotografias hemisféricas, aliadas as técnicas de mensuração da luz no ambiente (TONELI et al., 2007).

Algumas das limitações destes métodos são esclarecidas por Weiss et al. (2003): a demasiada simplificação da forma da folha, a dificuldade de ajustar a variação dos ângulos entre folhas, galhos e frutos em relação a radiação incidente levam a uma perda na precisão comparados a métodos diretos. Por outro lado, todos os métodos diretos de mensuração são difíceis e demorados quando se deseja medir grandes áreas. Por outro lado, algumas vantagens da fotografia hemisférica em relação a outros métodos são o baixo custo e a maior versatilidade do processamento na análise proporcionando maior número de variáveis relacionadas ao dossel.

As fotografias hemisféricas servem como registros semi-permanentes da geometria da abertura de clareiras e são utilizados em estudos de dinâmica do dossel da floresta para derivar parâmetros como Índice de Área Foliar (IAF), abertura do dossel e estimativa da penetração da radiação solar direta e difusa através das aberturas do dossel da floresta, bem como a transmissividade da radiação pelo dossel (HARDY, 2004). Anderson (1964) forneceu um tratamento teórico para o cálculo da penetração dos componentes direta e difusa da radiação solar através de aberturas de dossel, determinado através de fotografias hemisféricas.

As melhores fotografias hemisféricas, com alto contraste, podem ser obtidas um pouco antes do nascer do sol, pouco antes do pôr do sol ou sob um céu nublado. Mas alguns autores ressaltam que condições de retro-iluminação ideais não são muito frequentemente encontradas no campo (JELASKA, 2004).

Para análise das fotografias hemisféricas, pacotes de software comercial, bem como programas livres tem sido desenvolvidos e, consequentemente, usados em uma ampla gama de aplicações. Softwares como o Winscanopy (Regent Instruments, Quebec, Canadá), Solarcalc, Winphot (STEEGE, 1997), HemiView (Delta-dispositivo t, Cambridge, Reino Unido), Gap Light Analyser (FRAZER et al., 1997), CIMES (WALTER et al., 2003), de acordo com Jonckheere et al., 2005 vem sendo usados em diferentes aplicações. O fundamental do método é, no processamento da imagem, encontrar o limiar ideal de um valor de luminosidade para o ponto de imagem (pixel), bem como o limiar para distinguir a vegetação e a presença do céu (JONCKHEERE et al , 2004).

\section{Procedimentos operacionais}

Para o presente trabalho foram obtidas fotografias hemisféricas no bosque de manguezal em que vem ocorrendo, desde 2008, o levantamento de dados estruturais da vegetação (altura, diâmetro a altura do peito, densidade e dominância por espécie) e dados microclimáticos (temperatura e umidade relativa do ar, direção e velocidade do vento, precipitação, radiação solar global direta e refletida, emissividade terrestre e atmosférica).

Essa fotografia foi obtida por meio de uma câmera NIKON, Modelo F-501, acoplada por uma lente "fish eye" NIKOR $8 \mathrm{~mm}$ com ângulo de visada de $180^{\circ}$, conhecida como "lente olho-de-peixe".

No ambiente manguezal devido a sua particularidade de sedimento inconsolidado, não é possível o uso de tripé para fixar a máquina. Para sanar essa dificuldade, fixou-se um suporte de bambu que serve de apoio para o equipamento e de forma que a fotografia hemisférica é obtida sempre no mesmo ponto, para que assim se acompanhe a evolução do dossel ao longo do ano. A câmera fotográfica deve então ser posicionada sobre esse suporte, orientada para o Norte Geográfico e nivelada para que se possa obter a fotografia. As figuras 01 e 02 apresentam a instalação do equipamento no manguezal localizado no Litoral Sul de São Paulo, no município de Iguape/SP.

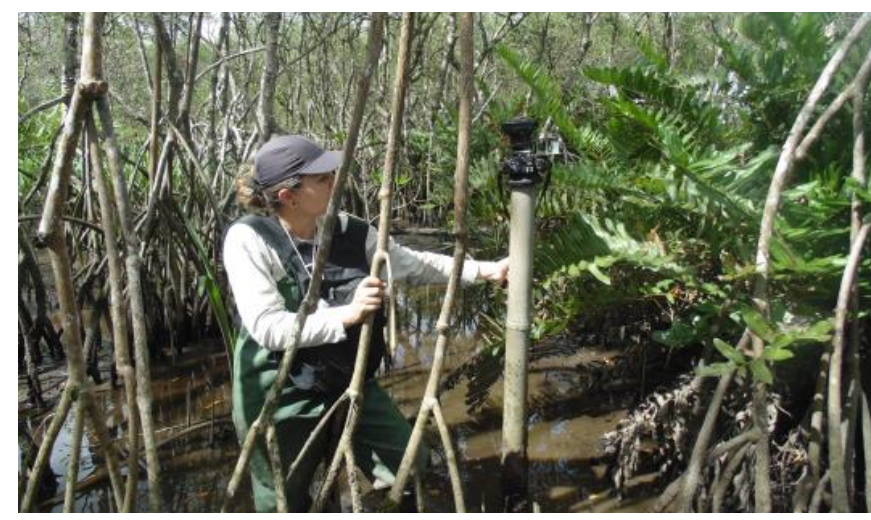

Figura 1: Câmera fotográfica acoplada com uma lente "olho de peixe", instalada no manguezal da Barra do Ribeira - Iguape/SP.

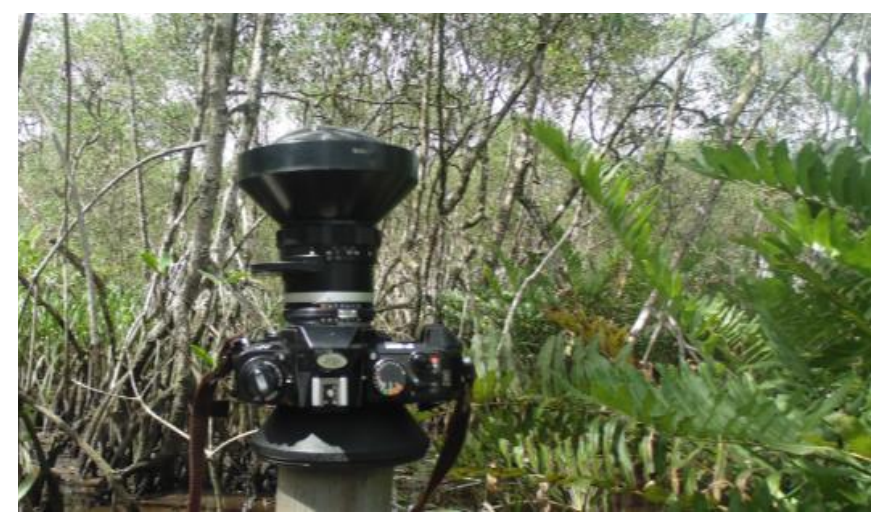

Figura 2: Câmera fotográfica com a lente "olho de peixe". 
Posteriormente, as fotografias foram processadas no software Gap Light Analiser - GLA versão 2. Foram obtidas sete fotografias hemisféricas nas seguintes datas: 27/05/2011, 27/08/2011, 10/12/2011, 05/02/2012, 22/04/2012 e 14/07/2012.

O software GLA tem sido usado para diferentes aplicações ao longo do mundo, como por exemplo, Simoni et al. (2003); Schnitzler e Closset (2003 ) ; Jelaska (2004); Crane e Shearer (2007) e outros.

A figura 03 apresenta dois exemplos de fotografias hemisféricas obtidas no manguezal da Barra do Ribeira - Iguape/SP, em 27/05/2011 e 27/08/2011.
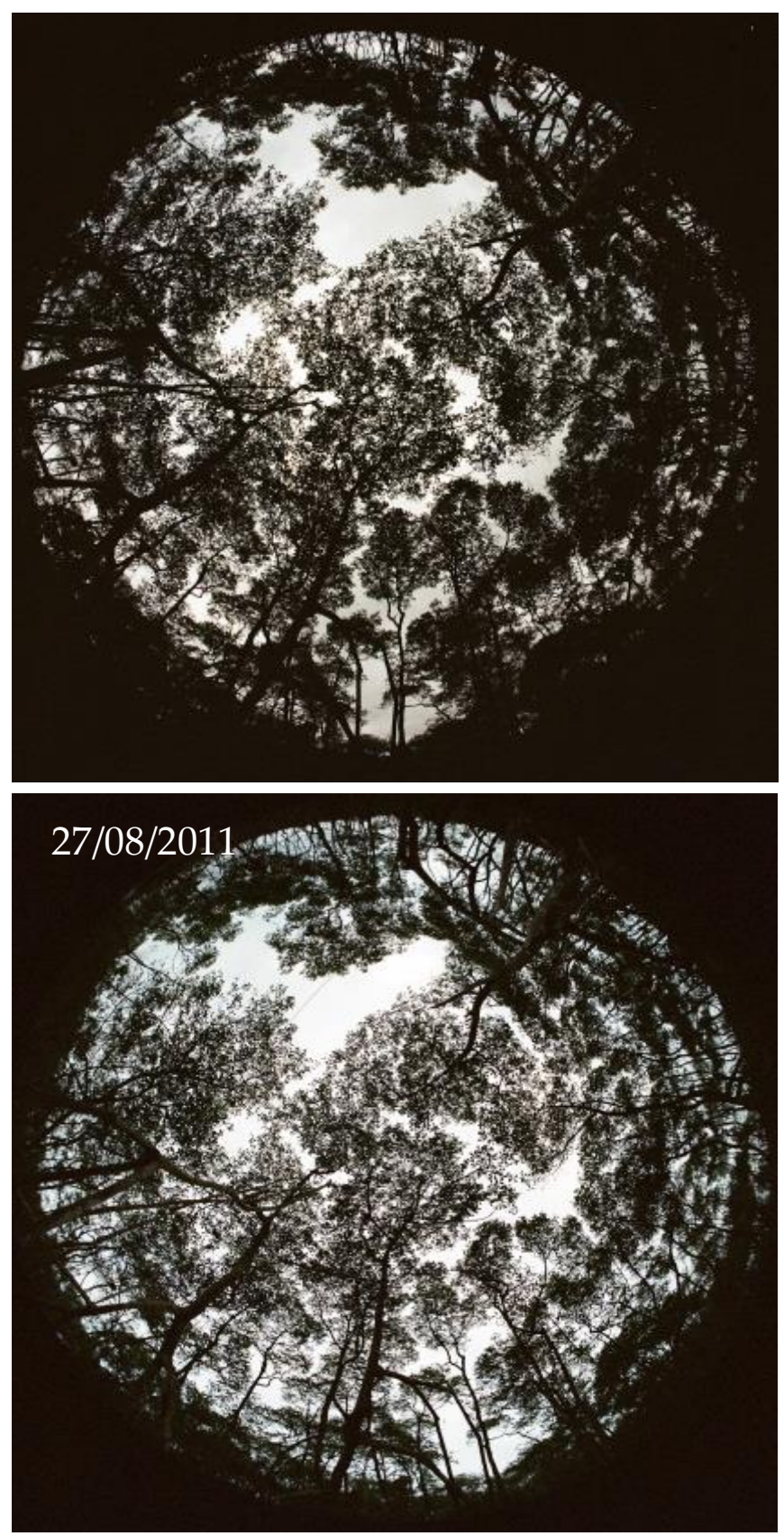

Figura 3: Fotografias hemisférica obtidas no manguezal da Barra do Ribeira - Iguape/SP em 27/05 e 27/08/2011, respectivamente.
Jarcuska (2008) destacou que uma das desvantagens do GLA é que ele realiza manualmente e de forma interativa, a seleção do valor de limiar para diferenciar a cobertura vegetal e o céu, o que pode gerar erros com a variação dependente do sujeito que da sensibilidade de quem processa a imagem. No entanto, autores como Jelaska et al, 2006 , também observado por Frazer et al (1999), Zhang et. al (2005) afirmam que uma forma de minimizar esse tipo de erro seria o de usar o canal do azul, considerado o melhor canal para a separação dos pixels entre classes de céu e da presença de vegetação. Vale destacar ainda, que apesar do IAF em sua definição estar relacionado apenas a área das folhas, o GLA não faz essa diferenciação, considera em sua análise também os galhos, flores e frutos.

No entanto, apesar de todas as limitações associadas a este método indireto para a avaliação dos dosséis florestais e iluminação sub-bosque (ROXBURGH; KELLY, 1995; JENNINGS et al., 1999), a fotografia hemisférica fornece uma ferramenta importante e útil em estudos ecológicos. Unificação e objetivação de técnicas de obtenção e avaliação de fotografias hemisféricas é importante em termos de melhoria da precisão e saídas de resultados comparação de diferentes fontes também (JARCUSKA, 2008).

A seguir são descritas as principais etapas na utilização do software Gap Light Analiser - GLA - versão 2, para análise das fotos hemisféricas, de acordo com Jonckheere et al., (2003).

1) Registro das fotografias: $O$ primeiro passo no programa GLA é registrar as fotografias, para que assim se identifique a orientação geográfica e a extensão circular da imagem hemisférica. Para isso é necessário a identificação de dois pontos conhecidos na imagem, o primeiro ponto, denominado ponto inicial, determina a orientação geográfica da imagem, enquanto o segundo ponto localiza-se de forma oposta ao azimute, ou seja, se o ponto inicial é $0^{\circ}$ norte o segundo será $180^{\circ}$ sul e marca a extensão circular da imagem.

2) Configuração dos arquivos de entrada: Os arquivos de entrada foram configurados para os modelos que o programa utiliza, incluindo informações de coordenadas geográficas (latitude/longitude), projeção, posição local (inclinação do relevo e aspecto de exposição solar), radiação solar incidente e condições atmosféricas.

3) Classificação da imagem: Quando a foto não possuía um bom contraste entre o céu e o dossel, aproximouse o limiar entre os valores de brilho para melhorar a classificação durante a análise da imagem. Por último, foi computado o processo de análise para geração dos resultados.

Para esse trabalho foram calculados apenas o Índice de área foliar (IAF), sendo utilizado o IAF efetivo integrado sobre o ângulo zenital de $0-60^{\circ}$, referido como LAI 4 no software GLA e a abertura do dossel, que refere-se a porcentagem do céu aberto visto sob um dossel da floresta. 


\section{Resultados}

A área foliar é uma importante característica estrutural para manguezal, assim como para qualquer tipo de cobertura arbórea, visto que é no dossel que ocorre significativos processos fundamentais para o ecossistema, como transpiração, interceptação de chuva, fotossíntese e, ainda, fornecem matéria orgânica para a serapilheira.

As Figura 4 e Figura 5 apresentam os resultados das fotografias hemisféricas obtidas no manguezal da Ilha dos Papagaios. A Figura 5 evidencia o ciclo de variação da abertura do dossel no manguezal em 2011 e 2012. Observa-se que a primeira medida ocorreu em maio com $24,7 \%$, em seguida destaca-se agosto com uma das maiores aberturas do período, com 35,3\%. A partir dessa data observa-se que a abertura tende a diminuir até o mês de abril quando se iniciou novamente o período de maior abertura do dossel.

Quanto ao IAF, apresentado na Figura 5, o menor valor foi registrado em 27/08/11, durante o inverno, com IAF de 1,12. Em termos de porcentagem, de 27/08/11 (período de menor IAF) a 22/04/2012 (período de IAF mais elevado) houve um aumento de $35 \%$.

Ao se comparar o valor estimado de inverno nos dois anos, observa-se que 14/07/12 apresentou um IAF mais elevado do que em 27/08/11 (IAF = de 1,58). Vale

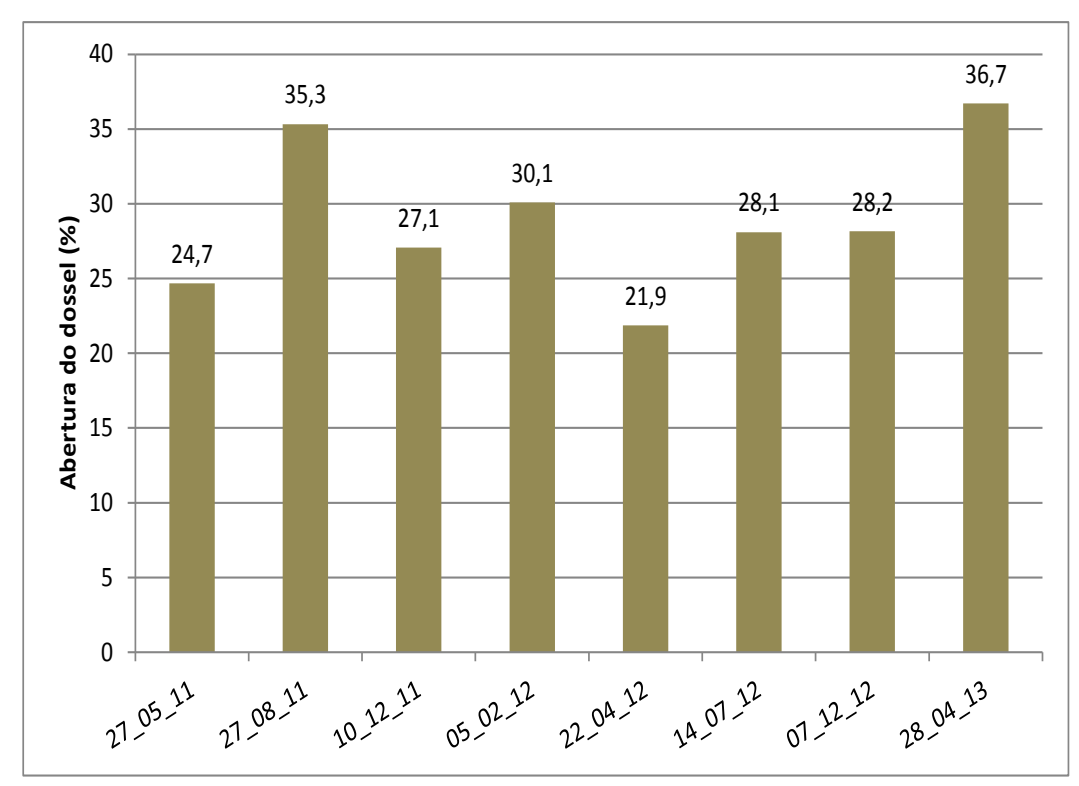

Figura 4: Variação da abertura do dossel (\%) estimada por meio de fotografias hemisféricas no manguezal da Ilha dos Papagaios - Barra do Ribeira - Iguape/SP.

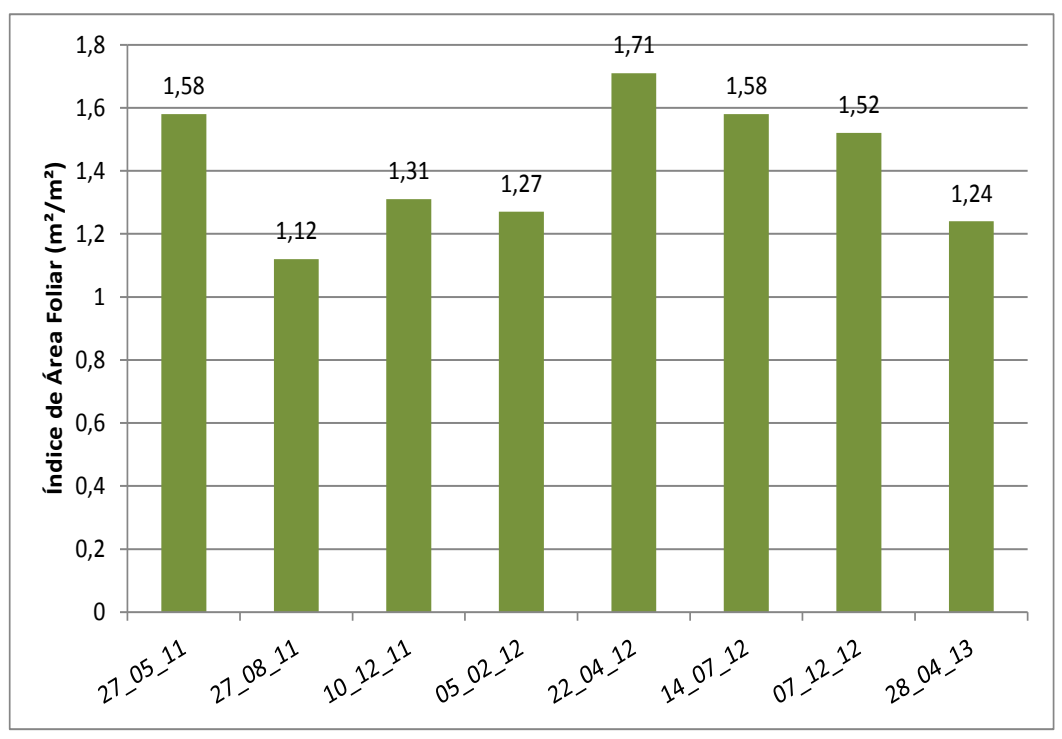

Figura 5: Variação do índice de área foliar estimado por meio de fotografias hemisféricas no manguezal da Ilha dos Papagaios - Barra do Ribeira - Iguape/SP. 
destacar que o mês de julho de 2012, apresentou uma precipitação mais elevada do que em 2011, o que pode ter contribuído para um maior número de folhas presente no manguezal nesse período. Enquanto em julho de 2011 registrou-se 125,8 mm, em julho de 2012 esse valor foi de $243,0 \mathrm{~mm}$.

Almeida (2005) estudou a produção de serapilheira no manguezal da Ilha do Cardoso, em Cananeia/SP. Para esse autor a produção de serapilheira apresentou marcante estacionalidade, com elevação das taxas de produção durante período mais úmido (verão) e diminuição no inverno.

A queda de folhas ocorreu durante todos os meses, observando-se picos para a Rhizophora mangle, espécie também dominante também na área de estudo do presente trabalho, entre outubro e abril, justamente o período de maior abertura foliar.

Destacam-se ainda os trabalhos realizados por Adaime (1985) e Menezes (1994), ambos em Cananéia, que também registraram maiores valores de produção de serapilheira durante meses mais chuvosos e de maior radiação solar, correspondendo aos dias de verão (dias mais longos e com maior número de horas de insolação). Vale destacar que o Índice de Área Foliar acaba refletindo o regime pluviométrico do período que o antecede, bem como a radiação solar disponível no ambiente.

\section{Considerações finais}

O uso de fotografias hemisféricas e a estimativa de parâmetros da cobertura vegetal, como índice de área foliar (IAF) e abertura do dossel, representam uma forma de avaliação das interações que ocorrem na interface superfície-dossel. As dificuldades e subjetividades não impedem o seu uso dentro dos estudos microclimáticos desde que considerados alguns aspectos das condições de controle: luminosidade, hora do dia, orientação e época do ano. No âmbito da Climatologia Geográfica ainda são poucos os trabalhos que se utilizam desta tecnologia nos estudos microclimáticos, espera-se com esse artigo fornecer subsídios para que novos estudos sejam implementados e o uso das fotografias hemisféricas ganhe espaço nas pesquisas geográficas.

\section{Agradecimentos}

Os autores agradecem ao $\mathrm{CNPq}$ (processo número 472473/2011-5) e a Fundação Boticário (edital Bio\&Clima Lagamar, Código: BL0006_20121) pelo financiamento concedido a presente pesquisa.

\section{Referências}

ADAIME, R. R. Produção do bosque de mangue da Gambôa Nóbrega (Cananéia, $25^{\circ}$ Lat.S - Brasil). Tese (Doutorado em Oceanografia) - Instituto Oceanográfico, Universidade de São Paulo, São Paulo, 1985.

ALMEIDA, R. Ecologia de manguezais; dinâmica da serapilheira e funcionamento do ecossistema, Ilha do Cardoso, Cananeia, São Paulo, Brasil. São Paulo, Tese de Doutorado, IOUSP, 183p.

ANDERSON, M. C. Studies of the Woodland Light Climate. Journal of Ecology, Cambridge, v. 52, n.3, p. 643-663, 1964.

BARRY, R.G.; CHORLEY, R. J. Atmosfera, tempo e clima. Tradução: Ronaldo Cataldo Costa. Porto Alegre: Bookman, 2013.

CRANE C. E.; SHEARER B. L. Hemispherical digital photographs offer advantages over conventional methods for quantifying pathogen-mediated changes caused by infestation of Phytophthora cinnamomi. Australasian Plant Pathology, 36, 466-474, 2007.

EVANS, G.D., COOMBE, D.E., 1959. Hemispherical and woodland canopy photography and the light climate. Journal Ecol. 47, 103-113.

FRAZER, G. W.; CANHAM, C. D.; LERTZMAN, K. P. Gap Light Analyzer (GLA), Version 2.0: Imaging software to extract canopy structure and gap light transmission indices from true-colour fishe eye photographs, users manual and program documentation. New York: Simon Fraser University Burnaby, B. C., 1999, 36 p.

FRAZER, G.W., TROFYMOW, J.A., LERTZMAN, K.P. 1997. A method for estimating canopy openness, effective leaf area index, and photosynthetically active photon flux density using hemispherical photography and computerized image analysis techniques. Canadian Forest Service, Pacific Forest Centre. Information Report. $\mathrm{n}^{\circ} \mathrm{BC}-\mathrm{X}-373$.

HARDY, J.P., et al. Solar radiation transmission through conifer canopies. Agricultural and Forest Meteorology 126, 257-270, (2004).

JARČUŠKA, B. Methodological overview to hemispherical photography, demonstrated on an example of the software GLA. Folia Oecologica, vol. 35, $\mathrm{n}^{\circ} 1,2008$. 
JELASKA, S.D. Analysis of canopy closure in the dinaric silver fir - beech fores (OmphalodoFagetum) in Croatia using hemispherical photography. Hacquetia 3/2, 43-49, 2004.

JELASKA, S.D., et al. Responses of forest herbs to available understory light measured with hemispherical photographs in silver fir-beech forest in Croatia. Ecological modelling 194 209218, 2006.

JENNINGS, S. B.; Brown, N. D.; Sheil, D. Assessing forest canopies and understorey illumination: canopy closure, canopy cover and other measures. Forestry, vol.72, $\mathrm{N}^{\circ} 1,1999$.

JONCKHEERE et al. Assessment of automatic gap fraction estimation of forests from digital hemispherical photography. Agricultural and Forest Meteorology 132 (2005) 96-114

JONCKHEERE, I. et al. Methods for leaf area index determination, Part I: techniques and instruments. Agriculture and Forest Meteorology. v. 121, n. 2, p. 37-53, 2003.

JONCKHEERE, I., FLECK, S., NACKAERTS, K., MUYS, B., COPPIN, P., WEISS, M., BARET, F. Review of methods for in situ leaf area index determination. Part I. theories, sensors and hemispherical photography. Agriculture Forest Meteorology, 121: 19-35, 2004.

MARQUES FILHO, A. O. Regime de radiação solar e características da vegetação - modelos de inversão. Acta Amazônica, v. 27, n. 2, p. 119-134. 1997.

MELO et al., Cobertura de copas como indicador de desenvolvimento estrutural de reflorestamentos de restauração de matas ciliares no médio Vale do Paranapanema, SP, Brasil. Revista Árvore, ViçosaMG, v.31, n.2, p.321-328, 2007.

MENEZES, G.V. Produção e decomposição em bosques de mangue da Ilha do Cardoso, SP. Dissertação (Mestrado em Oceanografia) - Instituto Oceanográfico, Universidade de São Paulo, São Paulo, 1994.

ROXBURGH, J. R.; KELLY, D. Short communication uses and limitations of Hemisferical photography for estimating forest light environments. New Zealand Journal of Ecology, New Zealand. v. 19, n. 2, p. 213-217, 1995.
SALVI-SAKAMOTO, L. L. Os microclimas e a "configuração do céu" na área central. In: Os climas na cidade de São Paulo: teoria e pratica. Org. José Roberto Tarifa e Gustavo Armani. São Paulo: PróReitoria de Cultura e Extensão. Universidade de São Paulo, 2001.

SCHNITZLER, A.; CLOSSET, A. Forest dynamics in unexploited birch (Betula pendula) stands in the Vosges (France): structure, architecture and light patterns. Forest Ecology and Management, 183, 205-220, 2003.

SIMIONI, G.; GIGNOUX, J.; LE ROUX, X. Tree layer spatial structure can affect savanna production and water budget: results of a 3-D model. Ecology, 84(7), pp. 1879-1894, 2003.

TONELI, et al. Analise da relação entre a estrutura do dossel a partir de fotografias hemisféricas e dados dendrométricos de inventario florestal, conduzido em um povoamento de Eucalyptus grandis. In: Simpósio Brasileiro de Sensoriamento Remoto, 8., 2007, Florianópolis. Anais...Florianópolis: INPE, 2007. p. 1891-1898.

WALTER et al. Integrating clumping effects in forest canopy structure: an assessment through hemispherical photographs. Canadian Journal of Remote Sensing, v. 29, nº 3, p. 388-410, 2003.

WANDELLI, E.V.; MARQUES FILHO, A.O. Medidas de radiação solar e índice de area foliar de coberturas vegetais. Acta Amazônica, n.29, p. 57-78. 1999.

WATSON, D.J. Comparative physiological studies in growth of field crops. I. variation in net assimilation rate and leaf area between species and varieties, and within and between yars. Annatomy and Botany. n. 11, p. 41-76. 1974

WEISS, M.; BARET, F.; SMITH, J. G.; JONCKHEERE, I.; COPPIN, P. Review of methods for in situ leaf area index (LAI) determination, Part II: estimation of LAI, erros and sampling. Agriculture and Forest Meteorology. v. 121, n. 1, p. 37-53, 2003.

ZHANG, Y.; CHEN, J. M. MILLER, J. R. Determining digital hemispherical photograph exposure for leaf area index estimation. Agricultural and Forest Meteorology 133, 166-181, 2005. 